\title{
O papel da narrativa no projeto da sociedade empreendedora e na cultura da inspiração

\author{
Vander Casaqui
}

Universidade Metodista de São Paulo, São Bernardo do Campo, São Paulo, Brasil

\section{Resumo}

O objetivo deste artigo foi tratar narrativas como objeto de estudo, no contexto do empreendedorismo e da cultura da inspiração, tendo como base a teoria de Bruner (1991).

Como objeto empírico, analisamos as micronarrativas de autoajuda empreendedora do Blog Geração de Valor, denominadas "charges", à luz da teoria de Bruner. Ao abordarmos criticamente o tema do empreendedorismo, compreendemos o papel fundamental das narrativas inspiracionais, que articulam contexto e materialidade discursiva, espírito do tempo e subjetividade, economia e trajetórias de vida.

\section{Palavras-chave:}

Comunicação e consumo. Cultura empreendedora. Cultura da inspiração. Narrativa. Discurso.

\section{Introdução}

Este trabalho trata do tema da narrativa, considerada como materialidade para o estudo do empreendedorismo e da cultura da inspiração no campo da comunicação, por meio da análise dos processos midiáticos e seus desdobramentos na vida social. Se partirmos do pressuposto que vivemos sob a égide do capitalismo comunicacional (PRADO, 2017), temos em conta que a narrativa tem uma função, para além de sua ancestralidade na cultura de forma geral, e faz parte indissociável da experiência humana. Na perspectiva do capitalismo comunicacional, de acordo com Prado (2017, p. 13), "a comunicação é uma atividade que atualmente molda a vida, não somente o consumo, a partir dos regimes de programação em direção do aumento do capital do eu empreendedor de si próprio". É a função estratégica da narrativa no contexto do capitalismo de nosso tempo que nos leva a traçar um percurso que interroga sobre a sua relação com a inspiração e com a retórica que serve de justificação ao sistema econômico e que 
se identifica com o espírito do tempo (BOLTANSKI; CHIAPELLO, 2009).

Na sua obra sobre o novo espírito do capitalismo, Boltanski e Chiapello (2009) estudam as formas de justificação do sistema econômico, ou seja, a promoção do engajamento de novos quadros, com o estímulo dirigido a indivíduos (preferencialmente os mais jovens) para tomarem parte em sua esfera produtiva. Para mobilizar esses "novos" trabalhadores, o capitalismo precisa de um espírito, de um paradigma que serve de modelo ideal para inspirar trajetórias de vida. Esse espírito precisa se renovar ciclicamente: por esse motivo, sua vinculação com o tempo, com o seu cenário histórico, é fundamental.

O processo de renovação retórica, ainda segundo Boltanski e Chiapello, é resultante da capacidade do capitalismo de incorporar as críticas de seus opositores, especialmente aquelas elaboradas em cenários de crise aguda do sistema. Sendo assim, o "novo" espírito do capitalismo, que corresponde ao momento atual, é derivado da apropriação de bandeiras revolucionárias identificadas com a esquerda que emerge dos movimentos juvenis e trabalhistas de maio de 1968. Se aquela geração sonhava com um "outro mundo", com uma nova sociedade, antagônica aos valores e ideais conservadores da época, hoje podemos encontrar alguns desses ideais no cerne da reproposição do capitalismo sob a égide do empreendedorismo. Esses ideais, esvaziados de seu sentido original, servem à manutenção de um "mesmo mundo", pois associam a revolução à inovação tecnológica para o mercado, à liberdade e à autonomia de empreender, enfim, de atuar dentro do próprio sistema.

No contexto atual, tem-se como ponto pacífico que o empreendedor é o modelo ideal, o ser paradigmático de nosso tempo (BOLTANSKI; CHIAPELLO, 2009; EHRENBERG, 2010; FREIRE FILHO, 2010). Sua imagem heroica serve de referência, de modelo de sucesso nesse momento histórico, por sua visibilidade midiática e centralidade na retórica do capitalismo atual. Em um período de desmonte das conquistas históricas em torno dos direitos trabalhistas, o empreendedorismo serve como antídoto, ou seja, é apresentado como a saída para a crise que se instaura no âmbito individual, a solução mágica para as problemáticas do trabalho e da vida como um todo.

O ideal empresarial de si é a expressão máxima do neoliberalismo no âmbito da subjetividade, que serve de dissimulação a transformações radicais no mundo do trabalho contemporâneo. A precarização do trabalho e dos vínculos empregatícios; a economia de plataforma e o processo de uberização; o trabalho intermitente e a atividade laboral baseada em projetos; o transbordamento da 
esfera organizacional para a vida como um todo - entre outros elementos que caracterizam um ataque estrutural às leis e direitos trabalhistas, ao que resta de iniciativas de bem estar social no mundo - oferecem como contrapartida a retórica potente que positiva o cenário. Nesse sentido, empreender se torna a panaceia, a tábua de salvação para as mazelas que atingem a classe que vive do trabalho, pois ressignifica o fracasso (desemprego, informalidade, efemeridade de contratos etc.) como oportunidade e possibilidade de alcançar o sucesso, a felicidade de ser chefe de si mesmo. É esse fenômeno que observamos a partir do objeto selecionado para este artigo, o Blog Geração de Valor.

E onde se insere a narrativa, afinal? Em uma teia social alimentada pela produção midiática e por processos comunicacionais complexos, a cultura empreendedora se dissemina e se legitima, por meio de discursos e narrativas, ou cadeias discursivas e sua atualização em novos elos (BAJTín, 2008)ํ. Defendida e publicizada por um sem número de institucionalidades, suportes midiáticos, por agentes que assumem a voz em nome do empreendedorismo e que ecoam a sua ideologia e as suas formações discursivas, a cultura empreendedora se revela como plurivocal, mas nunca como polifônica. Isso porque há uma espécie de monocultura empreendedora que corresponde à noção de sociedade positiva discutida por Byung-Chul (2013), que serve à dissimulação das graves consequências do capitalismo flexível que atingem os trabalhadores no contexto contemporâneo, como aponta o autor. Nesse sentido, é possível perceber, por vozes múltiplas, a consagração do empreendedorismo como um discurso social contemporâneo (ANGENOT, 2010), ou seja, como expressão do espírito de um tempo, como formação discursiva onipresente.

Por mais que tenhamos uma variedade de formas linguísticas e formatos midiáticos e uma gama de enunciadores que transitam da experiência da vida narrativizada ${ }^{2}$ como modelo inspiracional às prescrições gerais da sociedade empreendedora (DARDOT; LAVAL, 2016) - que se desenha pelo advento de uma nova racionalidade e pela produção da subjetividade neoliberal -, a imagem do empreendedor é reiterada de forma similar em suas

1 Utilizamos a obra de Bakhtin em sua edição em espanhol pela editora Siglo Veintiuno, por ser uma tradução feita diretamente da língua russa por Tatiana Bubnova, diferentemente das primeiras edições brasileiras, que foram traduzidas da versão francesa. Por esse motivo, a publicação citada neste artigo é uma edição mais recomendada por especialistas de suas teorias.

2 A noção de vida narrativizada, neste trabalho, é derivada da teoria de Bruner (1991), que considera que a comunicação dos acontecimentos da vida passa, necessariamente, pela sua transformação em narrativa. 
características e aptidões, com a mobilização dos mesmos modelos pré-construídos que caracterizam esse ator social. Entre as principais atribuições e competências do empreendedor estão: ser flexível, resiliente, transformador, inovador, criativo, disruptivo, heroico, visionário, bom gestor das próprias emoções. Esses e outros termos repisados pelas narrativas assumidas por empreendedores de sucesso, por coaches, por especialistas nas técnicas de si - que aqui identificamos como parte do universo da autoajuda - caracterizam aquilo que Byung-Chul (2013) denomina o inferno do igual, como expressão da positividade comunicacional dos agentes, das comunidades e das audiências alinhadas aos preceitos da cultura empreendedora.

Concluímos, diante desse cenário, que a cultura empreendedora é constituída a partir de uma comunidade imaginada, fundada em teias narrativas, que atualmente tem como suporte um sem número de dispositivos midiáticos e processos complexos de produção, circulação e consumo comunicacionais.

De acordo com Brockmeier e Harré (2003, p. 526), a narrativa é entendida como um "[...] conjunto de estruturas linguísticas e psicológicas transmitidas cultural e historicamente". Baseados na teoria narrativa de Bruner, os autores consideram que, "ao comunicar algo sobre um evento da vida - uma situação complicada, uma intenção, um sonho, uma doença, um estado de angústia - a comunicação geralmente assume a forma da narrativa, ou seja, apresenta-se uma estória contada de acordo com certas convenções".

A definição de Brockmeier e Harré (2003) considera que a narrativa é associada à esfera particular da experiência individual e, simultaneamente, remete à dimensão social, uma vez que "nosso repertório local de formas narrativas é entrelaçado a um cenário cultural mais amplo de ordens discursivas fundamentais, que determinam quem conta qual estória, quando, onde e para quem" (p. 527). Sendo assim, nesse âmbito em que particular e contextual se articulam, indivíduo e sociedade se relacionam de maneira intrínseca. Narrar é organizar a experiência pessoal e, simultaneamente, remeter a uma cultura, que abriga o compartilhamento da língua, de valores, de ideias e do sentimento de pertença a uma comunidade.

Essa dimensão linguística e cultural da narrativa, em perspectiva ampla, guarda vinculação com um contexto sócio-histórico determinado, com práticas sociais que são atravessadas pelo espírito do tempo, ou seja, pelos paradigmas de dada época, nas suas conformações e subversões. Nesse ponto, é importante destacar a relação estabelecida pelos autores entre discurso e narrativa 
- sendo o discurso a categoria mais geral, que remete às práticas comunicacionais que correspondem a certas institucionalidades, tradições e matrizes culturais, e a narrativa tratada como um tipo específico de discurso. No espectro da cultura empreendedora, entendemos que as cadeias discursivas remetem ao cenário social e à construção da realidade a partir de valores e ideologias alinhados com a perspectiva econômica e política do capitalismo. Nesse contexto, destacamos, neste trabalho, o papel das narrativas como formas específicas de materialização das cadeias discursivas associadas ao capitalismo de nosso tempo.

Estabelecemos como objetivo geral a compreensão da relação entre a construção narrativa da realidade discutida por Bruner (1991) e a cultura empreendedora, por meio da adequação dos elementos apontados pelo autor. Essa adaptação da teoria narrativa à leitura do empreendedorismo e suas multifaces serve de base à elaboração de um mapeamento de objetos e problemáticas que caracterizam o estudo dessa cultura no campo da comunicação e do consumo. Tratamos da narrativa como objeto de análise, por meio da qual acessamos as formações discursivas e as estratégias enunciativas, que por sua vez são articuladas com projetos de sociedade, com os preceitos da sociedade neoliberal.
Segundo Brockmeier e Harré (2003, p. 528), "não é apenas a narrativa que faz a mediação, expressa e define a cultura, mas também a cultura define a narrativa. Isso torna ainda mais difícil definir a narrativa como tal, isolada dos contextos de discurso nos quais ela é inserida por diversas convenções culturais". É nesse diálogo complexo entre narrativa, cultura e contextos de discurso que se situam os objetos de nossas pesquisas. A partir dessa adequação da proposta de Bruner sobre o estudo da narrativa, analisamos a produção comunicacional de um agente destacado dessa cultura na cena brasileira atual: trata-se de Flávio Augusto, responsável pelo Blog Geração de Valor e por produtos midiáticos derivados dele, como o portal meuSucesso.com e os livros de autoajuda Geração de Valor. O recorte para este artigo é uma seção de seu blog denominada "charges", composta por uma série de frases motivacionais que servem de síntese ao pensamento desse agente. Em formato de banner digital, esse material é elaborado para o compartilhamento nas redes digitais, como pílulas que expressam a cultura empreendedora e que, simultaneamente, compõem uma grande narrativa sobre a trajetória de sucesso do empreendedor.

\section{Características da construção narrativa da realidade}

De acordo com Bruner (1991), a narrativa é necessária ao ser social, que elabora 
e organiza narrativamente os acontecimentos humanos, a experiência, a memória; por seu caráter convencional, por ser uma forma cultural reconhecida e compartilhada em sociedade, é uma das expressões da natureza comunicacional que localiza o ser no mundo e em relação à "realidade". Por outro lado, a leitura de Bruner aponta para o caráter de edição do mundo que corresponde aos discursos, mais especificamente às narrativas. Para dar cabo da concepção de narrativa que desenvolve, o autor relaciona dez traços que a caracterizam, a saber:

- diacronicidade narrativa - a narrativa tem relação intrínseca com o tempo, por ser uma exposição de acontecimentos que se desenrolam em uma perspectiva durativa. Passado, presente e futuro são tempos que situam o sujeito em seu percurso narrativo.

- particularidade - a narrativa trata de particularidades, como acontecimentos e indivíduos, que são emblemáticas e alegóricas e, por isso, simultaneamente se associam a uma dimensão geral, às questões tidas como universais que servem de chave de interpretação de um grupo social, da condição humana, da sociedade que essa narrativa representa.

- Vínculos e estados intencionais - os eventos mobilizados pela narrativa colocam a ação humana como chave de leitura do que Bruner chama de "estados intencionais", quer dizer, as escolhas, valores, ideias e convicções dos seres narrativizados.

- Composicionalidade hermenêtica - essa característica é associada à expressão de significados e sua interpretação; parte-se da ideia de que a narrativa é pensada no diálogo com o outro, como forma de comunicação baseada em acontecimentos, experiências e situações, a partir dos quais se pode extrair a "moral da história", por assim dizer.

- Canonicidade e violação - a relação entre tradições narrativas, que servem de expressão tanto nas reiterações de formatos consagrados (cânone) quanto na subversão da tradição, na inovação, ou mesmo na ressignificação de pré-construídos de outras tradições; esses processos de manutenção ou ruptura fazem parte de uma estratégia comunicacional.

- Referencialidade - a relação da narrativa com o mundo se dá por verossimilhança, pela mobilização de elementos da realidade para ancorar os acontecimentos, as construções de personagens e suas trajetórias, as ideias que se pretendem universais. Nesse aspecto, ficcionalidade e realismo não são separados por fronteiras nítidas, pois são aproximados pelo caráter narrativo da construção da realidade.

- Genericidade - os modos de contar, isto é, os gêneros narrativos identificáveis de uma cultura, para Bruner só poderiam funcionar 
plenamente a partir da predisposição das "mentes e sensibilidades"3 de interpretá-los e de pensar por meio deles. Nesse sentido, os modos de narrar "podem ter o poder de influenciar na moldagem de nossos modos de pensamento, da mesma maneira que eles criam as realidades que seus enredos descrevem" 4 (BRUNER, 1991, p. 15, tradução nossa).

- Normatividade-as normas que organizam a narrativa são adequadas ao contexto, no sentido de corresponder à sua época e às circunstâncias de sua produção. Bruner, nesse ponto, relaciona a narrativa ao mundo cultural, que por sua vez guarda relação com as expectativas, visões de mundo e valores de uma época, transfigurados em formas de narrar. Há certa relação entre a expressão narrativa e o espírito do tempo que dá sentido às escolhas e modos de dizer do narrador.

- Sensibilidade de contexto e negociabilidadeaprofundando alguns aspectos anteriores, nesse tópico Bruner dá ênfase para a narrativa como negociação simbólica e se aproxima, de certa forma, da noção de auditório social (BAKHTIN, 1997). Essa perspectiva dialógica é entendida pelo autor como a interação de expectativas, que também nos remete à ideia de um leitor construído pela narrativa, pelo contrato comunicacional que emerge da leitura do contexto e das possíveis interpretações da mensagem.

- Acréscimo narrativo - como parte de uma cultura, as narrativas redimensionam a existência por meio de acréscimos, de conexões lógicas e de invenções de tradições, que fazem, por exemplo, de um relato autobiográfico algo similar à jornada do herói. Bruner considera esse elemento narrativo de especial interesse para antropólogos e historiadores, que teriam acesso às relações histórico-causais de uma determinada cultura, aos seus discursos fundadores, às mito-lógicas, elementos que reordenam experiências compartilhadas de uma sociedade. O passado, nesse sentido, é alvo de construções e reconstruções contínuas, de acordo com os novos cenários sociais em que a narrativa se projeta. Um exemplo mais particular, que nos interessa especificamente, é a chamada coerência por contemporaneidade, em que biografias e acontecimentos sociais mais abrangentes se entrecruzam em relações de causa e consequência formuladas narrativamente.

Os elementos apontados por Bruner são propriedades narrativas que operam na construção da realidade, que ganham sentido quando

"minds and sensibilities".

"they may have quite as powerful an influence in shaping our modes of thought as they have in creating the realities that their plots depict". 
incorporados a comunidades linguísticas e compartilhamentos culturais. Neste trabalho, refletiremos sobre esses aspectos no âmbito das narrativas da cultura empreendedora. Nosso objetivo é apontar caminhos possíveis de interpretação das contribuições de Bruner para as pesquisas sobre empreendedorismo com uma abordagem crítica e comunicacional.

\section{A Cultura Empreendedora como construção narrativa}

Neste tópico, apresentamos uma visão geral das conexões entre os elementos da teoria narrativa de Bruner e o cenário da cultura empreendedora. Identificamos a relação entre esses elementos e as conclusões a que chegamos até o momento, no desenvolvimento das pesquisas sobre a cena discursiva do empreendedorismo contemporâneo. Conforme apontam Brockmeier e Harré (2003, p. 533),

Ao mesmo tempo, as narrativas operam como formas de mediação extremamente mutáveis entre o indivíduo (e sua realidade específica) e o padrão generalizado da cultura. Vistas dessa maneira, as narrativas são ao mesmo tempo modelos do mundo e modelos do self. É através de nossas estórias que construímos a nós mesmos como parte de nosso mundo.

A cultura empreendedora é, sem dúvida, um padrão fundamental a partir do qual operam mediações narrativas que constituem os sujeitos. Sendo ao mesmo tempo "modelos de mundo e modelos do self", as narrativas de empreendedores são produzidas, circulam e são consumidas por uma profusão de meios, tendo como um dos suportes mais recorrentes as mídias digitais. A presença, ou melhor, a onipresença dessas narrativas na atualidade é entendida no espectro desta pesquisa como estratégica, no sentido de promover um modelo de mundo - a sociedade empreendedora idealizada por Drucker (2011) - bem como difundir modelos do self. Este último aspecto corresponde ao quadro de atitudes, comportamentos, predisposições psicológicas, apresentados como ideais no cenário do capitalismo flexível discutido criticamente por Sennett (2006, 2007). Nesse contexto, ser flexível, resiliente, positivo, "pró-ativo" e ter "atitude de dono" (mesmo quando se trata de um empregado, e não de um empreendedor no sentido estrito), entre outras características, caracterizam o selfideal para essa sociedade projetada nos parâmetros da cultura empreendedora. São traços e perfis reiterados por um sem número de vozes, entre empreendedores de palco, programas jornalísticos, blogs, relatórios de instituições que incentivam o empreendedorismo e publicações (de jornais diários a artigos científicos do campo da administração, por exemplo).

Em nosso percurso de pesquisa, iniciamos a imersão nesse contexto por meio dos 
discursos e narrativas de empreendedores sociais, em 2013. Apontamos que esse agente deveria ser analisado no entrecruzamento dos discursos que falam sobre seu papel social, e também por meio de suas próprias narrativas; comparativamente, percebemos que há um descompasso entre os discursos sobre empreendedores sociais e as suas próprias narrativas.

Por um lado, as narrativas dos agentes entrevistados oscilavam entre a identificação com a denominação de empreendedor social (devido à sua popularização recente) e o seu estranhamento, por conta da imagem hiperbólica de seu poder de transformação do mundo difundida na mídia. Esse acréscimo narrativo é visto com cautela e até reticência pelos próprios agentes, dadas as limitações e obstáculos para tornar um empreendimento social minimamente sustentável economicamente. Por outro, temos os discursos sobre esses agentes, que alimentam globalmente a sua imagem e seu papel social, que mobilizam o ethos messiânico para produzir as suas trajetórias de vida, nas quais o acréscimo narrativo é evidente. É isso que conclui a dissertação de mestrado de Sinato (2016), que tratou dos agentes da cena empreendedora social, reconhecidos e celebrizados pelas instituições agenciadoras globais como Ashoka, Schwab e Skoll Foundation. Os resultados desse estudo evidenciam que as trajetórias de vida dos empreendedores sociais - mediadas por institucionalidades e moldadas por sua perspectiva positiva - são alçadas ao patamar de narrativas míticas, de jornadas de heróis, que servem de alegoria e inspiração para o projeto de sociedade defendido pelos agenciadores da cena.

A particularidade opera em seu duplo vínculo com a dimensão genérica, quando as narrativas de indivíduos são adequadas à perspectiva de multiplicação do modelo ideal por meio do exemplo, definido como "inspirador". Essa é a estratégia comunicacional de uma série de instituições que assumem o objetivo de difundir a cultura empreendedora, como é o caso da Endeavor, uma das grandes agenciadoras do empreendedorismo no mundo. Um de seus objetivos principais é inspirar novos empreendedores de alto impacto: para tanto, promove eventos e produz materiais cujo fim é a difusão de seus modelos, das histórias de sucesso que correspondem ao seu projeto de sociedade.

Um dos exemplos dessa produção comunicacional da Endeavor associada à cultura da inspiração é o e-book 50 histórias para inspirar sua jornada empreendedora: um exemplo para chamar de seu (ENDEAVOR BRASIL/SEBRAE, s/d). O ato de inspirar por meio de narrativas, de histórias particulares, pode ser entendido também por meio do elemento narrativo composicionalidade hermenêutica, no sentido estratégico do diálogo com seu público, para que os preceitos 
mais abstratos da cultura empreendedora sejam mostrados de forma concreta, figurativizando a moral da história.

A referencialidade baseada em "fatos reais", ou seja, as narrativas de gente de "carne e osso" e de suas organizações e empreendimentos tem como objetivo favorecer a interpretação dos preceitos dessa cultura que se deseja propagar. Nesse aspecto, a característica narrativa dos vínculos e estados intencionais também é identificável, uma vez que seus atos e significados se combinam para caracterizar a jornada empreendedora, estruturada narrativamente para estimular seus leitores e convocá-los à ação, a mimetizar o exemplo em sua vida. O sucesso é demonstrado em atos, mas também em seus propósitos - um termo recorrente nessa cena, pois serve de legitimação das iniciativas em busca do lucro. O homo economicus, narrativizado como inspirador, ganha um caráter transcendente, por meio de valores associados às noções de vocação, de perseverança, de missão. A proximidade das narrativas inspiracionais com o discurso religioso não é por acaso, se considerarmos que a noção de inspiração tem em suas origens a vertente religiosa, como apontamos em estudo anterior (CASAQUI, 2017).

A noção que sintetiza a intencionalidade estratégica da Endeavor é a inspiração, que, em nossa pesquisa, corresponde a uma cultura e a um mercado. Isso significa que há um conjunto de práticas comuns denominadas inspiradoras, caracterizadoras da cultura da inspiração. Simultaneamente, a essa cultura corresponde um mercado, por haver uma série de ofertas de consumo (simbólico, material, cultural, de eventos) alimentadas por narrativas inspiracionais. Encontramos, dessa forma, a normatividade da narrativa nos modelos bem delimitados para servir a esse mercado da inspiração. No caso do mercado de palestras, o grande paradigma global são os chamados TED Talks, as palestras motivacionais que possuem o formato padrão de no máximo 18 minutos e um modelo compartilhado pelos palestrantes, para atingir o objetivo de "falar, convencer, emocionar" (GALLO, 2014) - como indica um dos manuais que ensinam o caminho das pedras para conquistar as plateias do evento.

Nesse ponto, outra característica narrativa apontada por Bruner se faz presente: a sensibilidade de contex to e negociabilidade é o elemento mobilizado como conhecimento a ser considerado pelo palestrante, para se adequar ao universo de expectativas, ao cenário construído para o compartilhamento de inspirações, pensadas como narrativas. Esse contexto dos TED Talks, por sua natureza de hibridação de formatos - visto que a oratória, como elemento central, é enquadrada na linguagem audiovisual dos vídeos produzidos, disponibilizados 
e exaustivamente compartilhados nas redes digitais -, leva Kedrowicz e Taylor (2016) a cunharem a noção de "electronic eloquence", ou eloquência eletrônica. Para os autores, essa eloquência é baseada na junção entre a "narrativa engajadora" ("engaging narrative") e uma presença visual marcante, composta pelo cenário padrão do evento, pela montagem audiovisual e pela indefectível apresentação em powerpoint - que agrega à narrativa oral as imagens que ancoram e expandem os significados e promovem efeitos como a curiosidade, o choque e o riso, entre outros recursos estratégicos para atrair a plateia (presente no auditório do evento ou mediada pelas tecnologias digitais).

A genericidade se manifesta de diversas formas reconhecíveis na cultura empreendedora; no caso específico da cultura da inspiração, associada à difusão do empreendedorismo, um dos formatos mais reconhecíveis é o da autoajuda, como aponta o estudo desenvolvido por Figueiredo (2018). O gênero narrativo da autoajuda, criado ainda no século XIX por Samuel Smiles, reconfigura-se nos tempos atuais, a partir dos preceitos do empreendedorismo. Dessa forma, o objeto estudado na pesquisa da autora - as narrativas biográficas e autobiográficas de expoentes da cena empreendedora de palco - foi denominado autoajuda empreendedora, pelo seu compromisso com a inspiração voltada à transformação de suas audiências, com vistas à adequação aos modelos e preceitos da sociedade empreendedora (DARDOT; LAVAL, 2016). Essa relação entre canonicidade e certo grau de subversão do gênero, ou a renovação da clássica autoajuda no âmbito do empreendedorismo de nosso tempo, marca o movimento da cultura, em sua adequação ao momento histórico, aos valores e expectativas de dada época.

Por fim, tratamos do primeiro elemento apontado por Bruner: a diacronicidade narrativa. A temporalidade é um dos elementos mais característicos da narrativa; para contar uma história, é necessário estabelecer um percurso, uma trama que se desenrola em certo tempo, em que o agente se vê às voltas com seus objetivos, em que os acontecimentos são elencados em certa ordem de encadeamento e sucessão. Dessa forma, a autoajuda empreendedora de Bel Pesce e Flávio Augusto tem como elemento fundamental a narrativização do passado para compor suas trajetórias de sucesso, como jornadas empreendedoras a serem tidas como exemplares para o seu público. Por outro lado, essas narrativas projetam um futuro imaginado para sua audiência, a ser construído seguindo as receitas de sucesso extraídas como lição da trajetória bem-sucedida. O contrato comunicativo da autoajuda pressupõe essa relação entre o passado narrado do enunciador e o futuro autoprojetado do enunciatário. 
Também destacamos nesse item a construção do futuro como narrativa, que, em nossa leitura, tem relação direta com os preceitos da sociedade empreendedora. Essa conexão se refere à noção de projeto de sociedade. No caso das narrativas que compõem nosso estudo, associamos a projeção futura ao objetivo de promover, de inspirar uma sociedade empreendedora, nos termos colocados por Drucker (2011). O autor concebe uma utopia pragmática, imaginada por meio do cenário onde os empreendedores seriam líderes da transformação social, de caráter reformista, tendo como base o sistema capitalista. As narrativas sobre o futuro como empreendimento e como resultado do empreendimento de si correspondem ao cenário da sociedade positiva discutida por Byung-Chul (2013). Como expressa a frase atribuída a Peter Drucker e popularizada em compartilhamentos nas redes sociais: "A melhor maneira de prever o futuro é criá-lo”.

Baseado na frase acima, o projeto Crie Futuros (<http://laladeheinzelin.com.br/crie-futuros/>) representa a hibridação narrativa também discutida por Bruner (1991). Em sua home page, encontramos ilustrações produzidas nas primeiras décadas do século XX que remetem a uma arqueologia do futuro (JAMESON, 2009). Essas imagens antigas servem à retórica que coloca a imaginação de futuro exercida no passado como o ponto de partida, o primeiro passo para sua concretização, em avanços identificados no presente.

Nesse aspecto, as inovações tecnológicas concebidas como futuros ilustrados são associadas a tecnologias desenvolvidas décadas depois, em clara conexão de causa e efeito, que guarda relação com a noção de acréscimo narrativo (BRUNER, 1991). Sem contar que a seletividade da escolha deixa de lado um sem-número de imagens de futuro que pouco ou nada correspondem ao presente. Na organização narrativa, o sonho de futuro passado criou o mundo em que vivemos, pela vontade de homens que devem servir de inspiração para uma nova geração de futuristas e seus seguidores. Mais uma vez, identificamos uma expressão da psicologia positiva aplicada à cultura empreendedora, tão reconhecível nos discursos de autoajuda atuais.

\section{A realidade construída como narrativa do Blog Geração de Valor}

O Blog Geração de Valor é o objeto deste trabalho por sua significância na cena do chamado empreendedorismo de palco. Flávio Augusto da Silva, o agente que encabeça esse projeto narrativo, é empreendedor, palestrante e autor de livros de autoajuda empreendedora, os best-sellers intitulados Geração de Valor - série que já está em seu quarto volume, na qual basicamente são compilados os pensamentos e frases difundidos inicialmente pelo 
blog. Como empreendedor de sucesso, Flávio Augusto é fundador da escola de línguas Wise Up, autointitulada "líder no ensino de inglês para adultos". Para além desse negócio, Flávio se tornou notório por ser proprietário de um clube de futebol masculino, o Orlando City, participante da liga norte-americana.

O nome do blog, Geração de Valor, traz um sentido dúbio: por um lado, faz referência à produção de valor, algo relacionado à atividade empreendedora e aos modos de produção capitalista - valor que pode ser entendido como econômico, mas também como valor social atribuído ao empreendedor - e, por outro, alude à ideia de geração, à comunidade imaginada e amarrada às teias de sentido sustentadas pelas narrativas inspiracionais. Essa segunda leitura é corroborada pela frase " $\mathrm{Eu}$ sou GV", utilizada para denominar os representantes do blog e seus seguidores, a audiência do Geração de Valor.

O aprendizado da língua inglesa da Wise Up está articulado a uma abordagem de desenvolvimento pessoal, como descreve o site da escola:

Além de técnicas desenvolvidas para ensinar adultos a falarem inglês, a metodologia da Wise Up é toda baseada em um conteúdo exclusivo, sobre oratória, coaching, negociação, liderança, gerenciamento estratégico, empreendedorismo e disciplinas que colaboram com o crescimento pessoal e profissional de nossos alunos. ${ }^{5}$

A proposta do curso nitidamente se aproxima de um treinamento inspirado em técnicas que se identificam com a pedagogia da autoajuda, discutida por Marín-Diaz (2012). Para a autora, a busca da felicidade e do sucesso, bem como a interpelação para que a audiência assuma uma jornada de autotransformação, são elementos que identificam o gênero narrativo da autoajuda (Figura 1). Com base nos pressupostos da teoria de Foucault, Marín-Diaz (2012) compreende esse gênero como antropotécnica, como técnica de si, que guarda relação com a pedagogia, por se colocar como saber necessário para a sua audiência, em tom didático, assertivo e, por vezes, imperativo. A incorporação desses elementos da autoajuda é dissimulada em propostas pedagógicas (muitas vezes, pseudopedagógicas), que se justificam por assumir como objetivo o desenvolvimento de competências técnicas requeridas pelo mercado de trabalho e pelos ambientes de negócios, principalmente associadas ao empreendedorismo, como é o caso da Wise Up. Desenvolvimentos pessoais e profissionais se confundem, amplificando o sentido da tese foucaultiana de que o empreendedor 
é, antes de tudo, empreendedor de si mesmo

(FOUCAULT, 2008) ${ }^{6}$.

Figura 1: Charge do Blog Geração de Valor de 25 de agosto de 2018
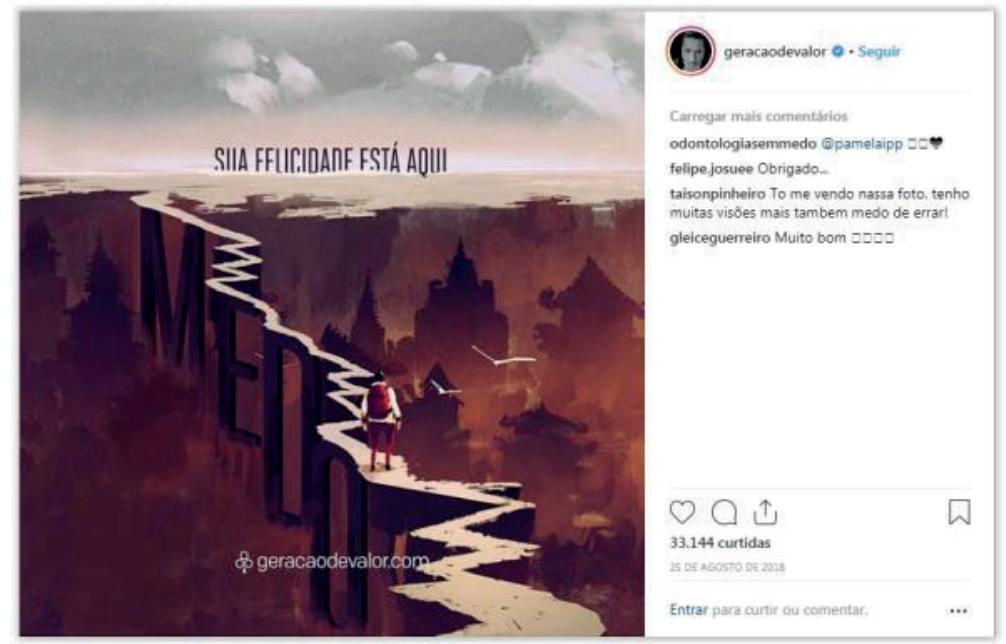

Fonte: Instagram do Blog Geração de Valor (2019). Disponível em: < https://www.instagram.com/geracaodevalor/>. Acesso em: 2 fev. 2019.

A audiência projetada no gênero da autoajuda é composta por gente que deve aprender sobre si mesma, sobre o sentido oculto do self que só se revela com o despertar do "empreendedor interior". Em sentido abrangente, temos a apoteose do ideal empresarial de si, baseado na autogestão do capital humano, para se tornar mais produtivo, eficaz, racionalizado. A inteligência emocional é fundamental nesse projeto de sociedade, sobretudo no aspecto da formação de mentalidades, em plena sintonia com os preceitos da sociedade positiva, como discute Byung-Chul (2013). A síntese dessas ideias aparece na postagem do blog de 23 de julho de 2018: "Empreender não é criar um CNPJ: é investir na empresa chamada sua vida" (Figura 2). 
Figura 2: Charge do Blog Geração de Valor de 23 de julho de 2018

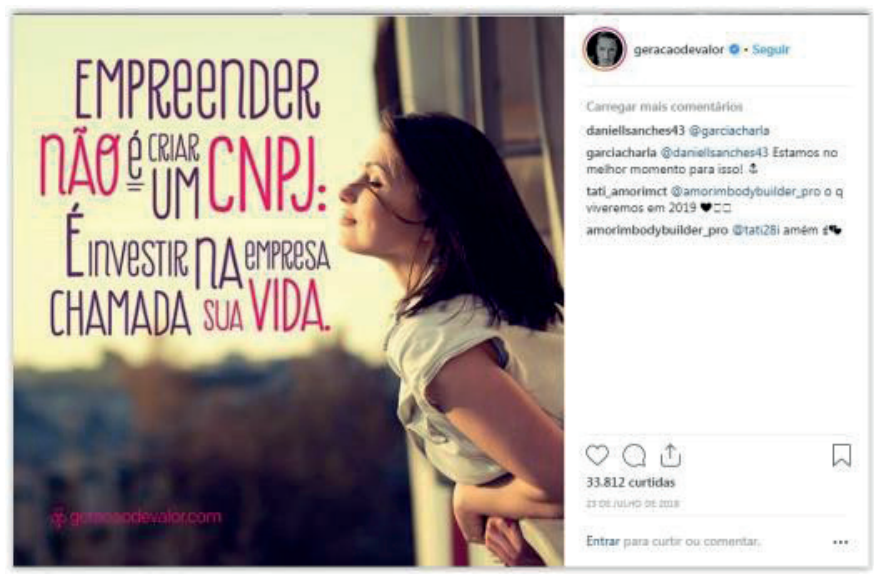

Fonte: Instagram do Blog Geração de Valor (2019). Disponível em: < https://www.instagram.com/geracaodevalor/>. Acesso em: 2 fev. 2019.

No Blog Geração de Valor encontramos uma seção que nos interessa especificamente, denominada "charges". Nela estão compilados todos os posts produzidos e colocados em circulação na mídia digital, tanto no Facebook quanto no Instagram - plataformas nas quais são compartilhados pela audiência que se identifica com essas ideias. As charges do blog são compostas por frases curtas, geralmente associadas a imagens e ilustrações que complementam ou amplificam o sentido da frase. Os números reforçam a importância do blog como objeto de estudo: na contagem divulgada na página do Instagram (https://www.instagram.com/geracaodevalor/, acesso em: 29 jan. 2019), são cerca de 2.700 publicações até o momento da redação deste artigo, acompanhadas por 1,6 milhão de seguidores.
Desse universo, analisamos as postagens publicadas no período de um ano, de janeiro de 2018 a janeiro de 2019; esse prazo foi determinado após observação prévia de todas as postagens do blog. Nesse processo de leitura, identificamos a repetição de postagens de um ano a outro, com pouca ou sem qualquer mudança, bem como a presença de uma série de fotografias de viagens de negócios, de lazer e registros da convivência familiar, que escapam ao formato das "charges". Basicamente, verificamos que o espectro de ideias do blog se esgota em cerca de um ano e é replicado no ano seguinte, com ligeiras variações.

Em nossa leitura da grande narrativa que compreende o conjunto de postagens das "charges", o principal significado das fotografias de viagens e da presença em família, que 
ocupam principalmente o primeiro período do blog, é essa construção do discurso competente associado ao seu fundador. A autoajuda é o discurso que promove a busca da felicidade e do sucesso como propósito humano e que pressupõe a transformação de si. O enunciador, nesse caso, demonstra que sua trajetória atingiu esses objetivos, tanto na vida pessoal quanto na profissional, para enfim falar com autoridade sobre a transformação necessária de seus seguidores, por meio das "charges". Essa primeira fase, com predominância de fotografias pessoais, vai da postagem inicial, no dia 16 de agosto de 2011, até 17 de julho de 2012, quando é publicada a primeira "charge", uma micronarrativa motivacional. A partir desse momento, as fotos dividem espaço com as "charges", que passam a ser maioria no conjunto das postagens.

A partir desse ponto, analisamos o corpus selecionado das "charges" motivacionais do Blog Geração de Valor, guiados pelos elementos narrativos propostos por Bruner.

A diacronicidade narrativa, que estabelece a relação do acontecimento com a dimensão temporal, é um dos elementos fundamentais no discurso da autoajuda. Passado, presente e futuro se organizam de modo a transmitir a ideia de jornada transcendente, de percurso de sucesso que serve de exemplo inspirador do enunciador, para que a audiência se identifique com isso e projete nele sua vida passada, seu momento atual, seus sonhos futuros.

O passado representa o ponto de partida, o surgimento do sonho ainda distante, o que amplifica a grandeza da conquista, da superação, da vitória no presente. Essa relação entre o passado, ou seja, o momento em que o sonho é concebido, com o presente, em que o sucesso é comprovado, tornado visível, materializado, é recorrente nas narrativas de vida de sujeitos que se apresentam como bem-sucedidos. É curioso perceber como as micronarrativas, as chamadas "charges", servem de desdobramentos à grande narrativa de sucesso de Flávio Augusto. Nota-se o recorrente esforço desse enunciador de revelar a própria história para demonstrar a autenticidade de suas ideias e a legitimidade de seu lugar de fala, como especialista na arte de inspirar para o empreendimento de si. Um exemplo é a imagem publicada em 12 de maio de 2018 , com o título "Reunião com os primeiros funcionários da WiseUp" (Figura 3), que mostra a foto de uma sala sem móveis no centro da cidade do Rio de Janeiro, em que Flávio Augusto, de pé, fala com um grupo de oito pessoas sentadas no chão forrado com papelão. Uma data ancora temporalmente a cena: 1995. Nos comentários da postagem ficam evidentes dois pontos: tanto a reiteração da dificuldade vivida naquele momento inicial 
Figura 3: Charge do Blog Geração de Valor de 12 de maio de 2018
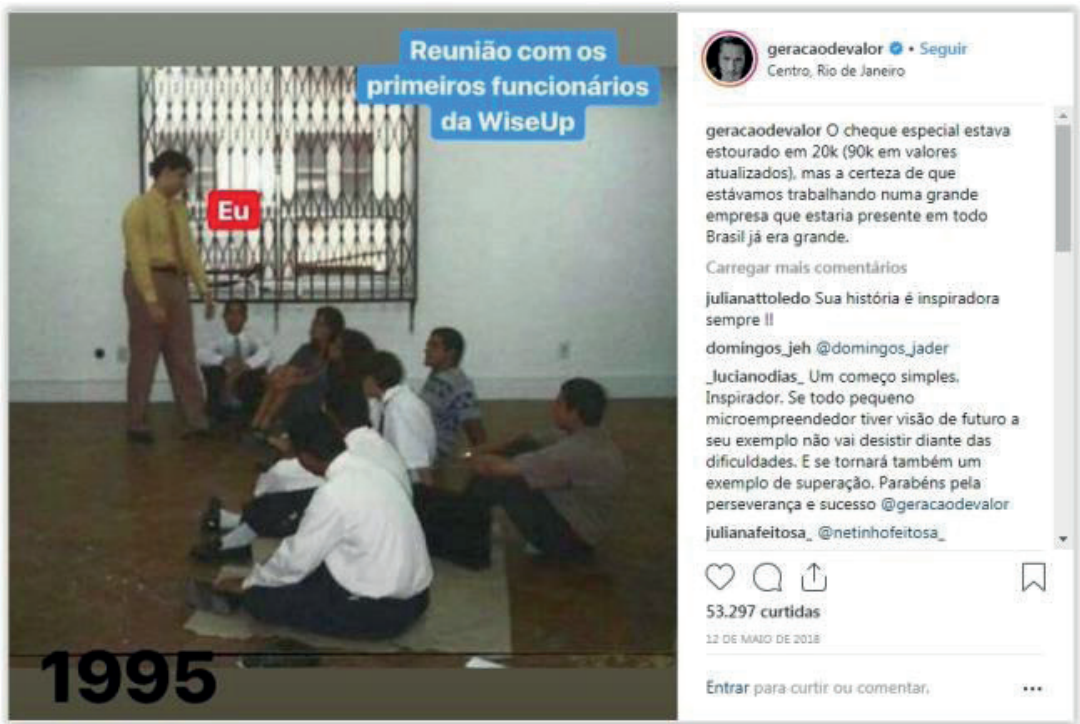

Fonte: Instagram do Blog Geração de Valor (2019). Disponível em: < https://www.instagram.com/geracaodevalor/>. Acesso em: 2 fev. 2019.

pelo personagem da narrativa, o que alimenta a estrutura da narrativa de superação, quanto a manifestação dos seguidores de que se trata de um exemplo "inspirador".

Obviamente, esse e outros exemplos específicos remetem ao elemento da particularidade, pois a dimensão pessoal serve de alegoria e é projetada como chave de interpretação para o estilo de vida ideal articulado à atividade empreendedora. Também guardam relação com os vínculos e estados intencionais, visto que as convicções, valores e lições do enunciador são transmitidos em tom imperativo, visando interpelar o outro como um ser a se autotransformar, a seguir a convocação como via única para uma vida de felicidade e sucesso.
Há outras nuances relativas à questão temporal nas narrativas do blog: o passado pode ser fonte de aprendizado e de experiências produtivas, pode servir ao reconhecimento dos fracassos e das fraquezas. No entanto, não pode ser um "peso" na trajetória empreendedora, que é voltada primordialmente ao futuro. Enquanto o post de 25 de dezembro de 2018 dá a "dica para perder peso: deixe o passado no passado"; em 16 de janeiro de 2019 temos uma paródia do desafio que se tornou viral nas redes sociais recentemente, intitulado "\#1oyearschallenge", no qual os internautas postam uma imagem de dez anos atrás, e uma recente ao lado, produzindo significados diversos na comparação. No caso do Blog Geração de Valor, o ponto de partida é o momento 
da postagem, 2019, em que há a imagem de um homem sorrindo, com o olhar dirigido ao leitor; essa imagem é ladeada por um espaço em branco, tendo como título "2029" e abaixo a seguinte mensagem: "Só depende de você". O futuro é resultado de uma construção pessoal, de um empreendimento de si.

A autoajuda empreendedora é situada como mediadora do processo de incorporação dos preceitos e do estado mental necessários para atingir esse sonho projetado no passado que deve ser planejado, calculado, racionalizado, colocado em ação no presente, para que possa acontecer no futuro. Como diz o post de 23 de setembro de 2018: "Sucesso não vem com o tempo. Vem com trabalho". O presente é a dimensão desse fazer, do trabalho em exercício para a produção do futuro desejável. Todos os comportamentos e sentimentos que impedem essa atividade, como a procrastinação, o "coitadismo", o medo (ver Figura I), devem ser anulados, superados, bem aos moldes da psicologia positiva popularizada pela autoajuda.

Como apontamos anteriormente, as imagens de Flávio Augusto servem de referencialidade recorrente, que ancora o universo de ideias, de frases e ditames relativos à sua autoajuda empreendedora com os acontecimentos de sua vida profissional e pessoal. A narrativa mítica do empreendedor transita entre a imaginação de si como herói e a verossimilhança desse imaginário, tornado visível na vida midiatizada do enunciador - em que felicidade e sucesso se tornam imagens. Simultaneamente, nessa grande narrativa, operam a ancoragem referencial e o acréscimo narrativo - pela expressão da jornada heroica projetada a partir do empreendedor. Essa dimensão heroica é, de certa forma, autoatribuída, em sintonia com a canonicidade da autoajuda.

Uma expressão emblemática desse elemento é a publicação de 16 de dezembro de 2018 , em que um homem, todo vestido de preto e com chapéu coco, olha-se no espelho e vê o reflexo de suas roupas, mas sem o rosto. O título ancora a imagem que parece ser extraída da obra do clássico pintor surrealista René Magritte (1898-1967): "Sabe a pessoa perfeita que você idealiza? Só você pode ser ela" (Figura 4). A mensagem explicita: o espelho é o outro, o espelho é você mesmo. Inspire-se nos heróis, seja mais herói que eles. Só depende de sua força interior.

A publicização da trajetória heroica para inspirar o outro se relaciona com a genericidade, uma vez que essa interpelação ganha sentido quando considerada em seu contrato comunicativo, em que o leitor, em tese, está predisposto a ser inspirado, a receber e assimilar as receitas de sucesso para sua vida. 
Figura 4: Charge do Blog Geração de Valor de 16 de dezembro de 2018

Compreendemos o elemento narrativo da normatividade como a adequação dos preceitos da autoajuda ao espírito do tempo; mais especificamente, a esse momento histórico em que o empreendedor se torna herói de uma era, como aponta Ehrenberg (2010). Nesse aspecto, por meio do Blog Geração de Valor identificamos que o empreendedor agrega elementos transcendentes, como a capacidade de ser um líder visionário, capaz de não só enxergar o futuro como também de construí-lo, mobilizando outros sujeitos para transformar o mundo a partir de suas convicções. Aqueles que o consideram "louco", que buscam desestimular o sonho desse ser heroico, são os invejosos, os losers. No post de 7 de novembro de 2018, temos um título que corresponde a essa abordagem: "Vai ter muita gente dizendo que não vai dar certo. Acredite em você" (Figura 5).
A trajetória de sucesso é simultaneamente uma jornada pessoal e um trabalho de equipe; no entanto, há nas "charges" o esforço recorrente de afirmar que esse ser bem-sucedido não faz parte da maioria. Trata-se de um líder a ser seguido. São diversas as postagens que buscam caracterizar o que é esse líder; entre eles, destacamos a de 19 de junho de 2018, que tem como título: "Liderar é gerir emoções" (Figura 6). A imagem traz um coração preenchido por rostos de homens e mulheres, de características diversas, mas com um padrão evidente: todos estão sorridentes; logo, todos são felizes. Essa liderança imaginada pelo blog é capaz de destinar felicidade aos seus liderados. As práticas de gestão, que envolvem ganhos financeiros, poder, hierarquias, lógicas de desempenho e racionalidade econômica, são reduzidas à administração dos 
ID 1850

0 papel da narrativa no projeto da sociedade empreendedora e na cultura da inspiração

\section{Figura 5: Charge do Blog Geração de Valor de 7 de novembro de 2018}
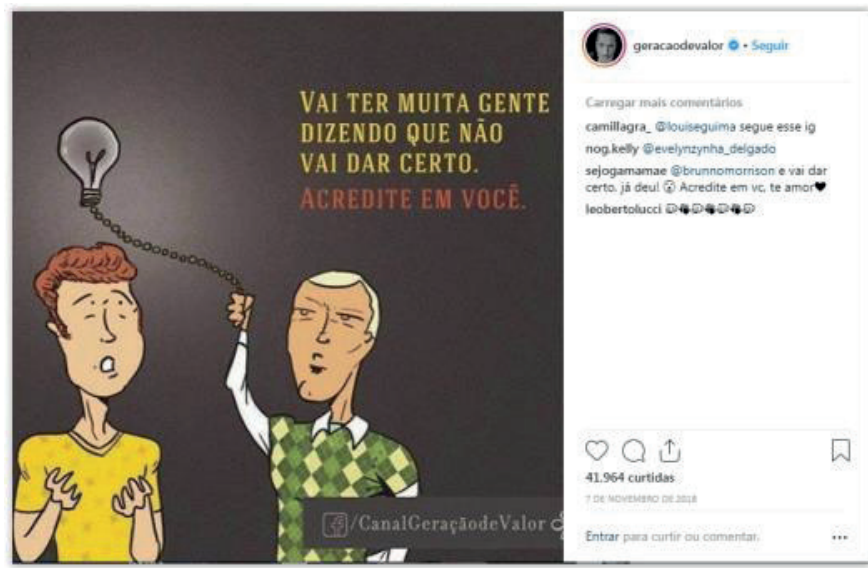

Fonte: Instagram do Blog Geração de Valor (2019). Disponível em: < https://www.instagram.com/geracaodevalor/>. Acesso em: 2 fev. 2019.

Figura 6: Charge do Blog Geração de Valor de 19 de junho de 2018
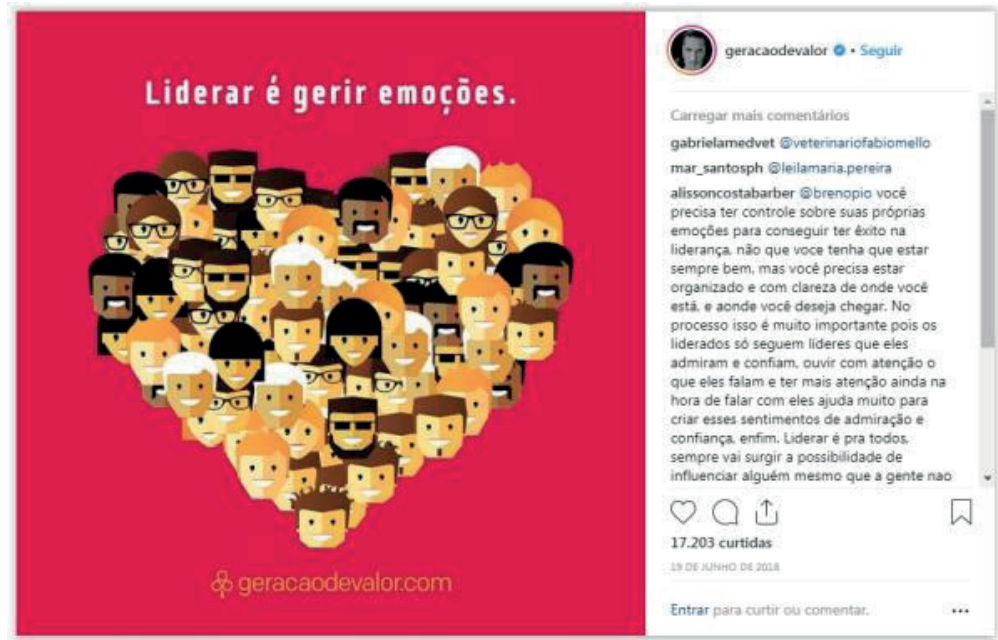

Fonte: Instagram do Blog Geração de Valor (2019). Disponível em: < https://www.instagram.com/geracaodevalor/>. Acesso em: 2 fev. 2019. 
afetos. Para o blog, o resultado da produção e reprodução do capital é a simulação da felicidade, e não o lucro, que por vezes é preservado pela crescente precarização das condições de trabalho.

Por ser um líder visionário, na construção narrativa do blog, o empreendedor é despregado do contrato social que envolve o bem comum. Suas convicções e atos devem ser livres, partindo-se do pressuposto que os seus "propósitos", valores e ideais correspondem ao que é melhor para todos, pois promoveriam o progresso, o bem-estar econômico. Essa noção de liberdade está diretamente relacionada com a racionalidade da sociedade neoliberal (DARDOT; LAVAL, 2016), em que o mercado é representado como positivo e imaculado, capitaneado por agentes moldados em sua subjetividade pela lógica neoliberal, que os projeta como semideuses, como seres apolíticos e gestores eficazes de seu capital humano. Já o Estado é construído como antítese na perspectiva do Geração de Valor, como obstáculo para a realização dos sonhos e projetos do homo oeconomicus - que assume o futuro de sua sociedade, mas que não reconhece as limitações de seu papel na divisão social do trabalho.

Tido como obstáculo à sociedade empreendedora, o Estado deve ser enxugado, privatizado, tornado mínimo. Como podemos ver na publicação de 10 de maio de 2018 , em que a imagem de um banheiro apresenta o título impresso sobre um rolo de papel higiênico: "Melhor empresas privatizadas do que públicas com serviço de privada" (Figura 7). O significado de privada, articulado com a imagem, não se refere exatamente a uma empresa privada; tem aspecto pejorativo, negativo, pois associa esse termo ao vaso sanitário - também conhecido como privada no senso comum. Por extensão, os dejetos são identificados com o serviço público.

Os direitos trabalhistas também são enquadrados na retórica negativa sobre o Estado e suas políticas públicas; na narrativa do blog GV (Fig. 8), correspondem à falta de liberdade, a uma forma de escravidão, à ausência de propósito e paixão, à vida sem sentido. As garantias são reservadas para gente incapaz de atuar com sucesso seguindo as lógicas do capitalismo flexível: assumindo riscos, sem vínculos, com resiliência, propósito, sonhos e atitude pragmática. Diversas postagens do blog constroem esse ser paradigmático, olimpiano, heroico. Um herói de todos os dias (BUONANNO, 2011), que ostenta e espetaculariza suas ideias e sua trajetória como paradigmáticas, exemplares, inspiradoras. A cultura da inspiração é o cenário onde Flávio Augusto desempenha sua entrada em cena e transforma seus sucessos nos negócios e na vida em performance midiática, que por sua 
Figura 7: Charge do Blog Geração de Valor de 10 de maio de 2018

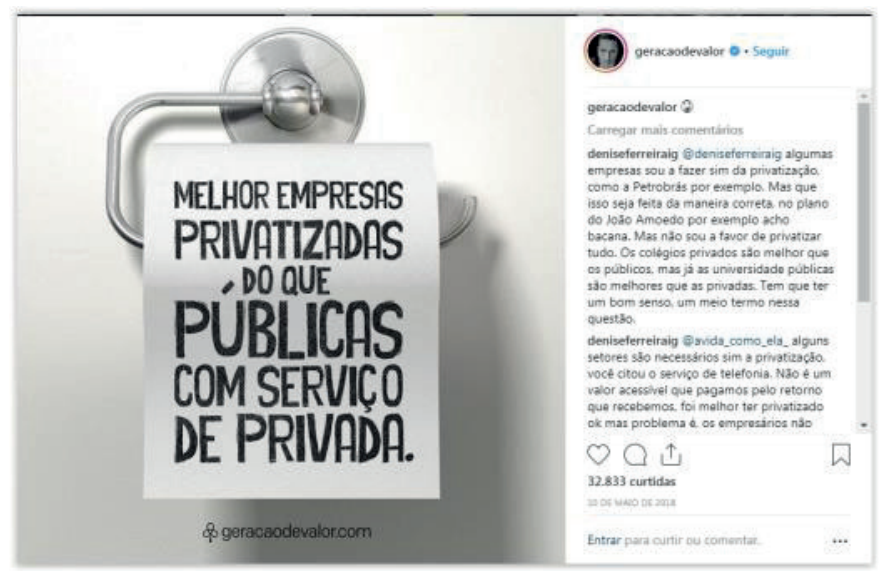

Fonte: Instagram do Blog Geração de Valor (2019). Disponível em: < https://www.instagram.com/geracaodevalor/> Acesso em: 2 fev. 2019.

Figura 8: Charge do Blog Geração de Valor de 22 de abril de 2018

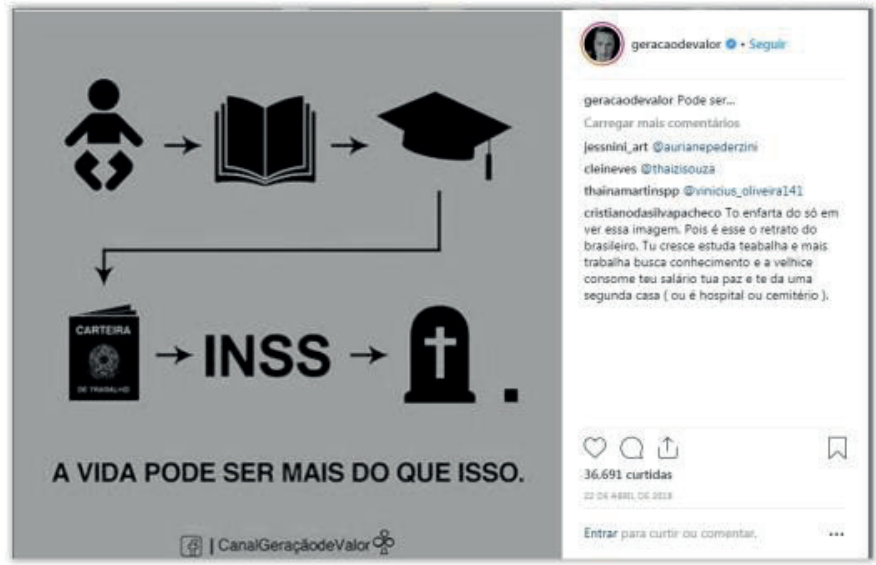

Fonte: Instagram do Blog Geração de Valor (2019). Disponível em: < https://www.instagram.com/geracaodevalor/>. Acesso em: 2 fev. 2019. 
vez gera mais ganhos econômicos no mercado das ideias da autoajuda. A mercantilização da vida ganha sentido quando situada nesse contexto inspiracional.

A trajetória de sucesso, de forma predominante na grande narrativa do Blog Geração de Valor, só dependeria da inteligência emocional e da força interior. Essa mentalidade empreendedora é narrada como uma espécie de religião, com seus dogmas, com suas crenças, com a pregação da fé em si mesmo. A "charge" de 9 de abril de 2018 explicita essa lógica: "Esqueça as más notícias. Foque na sua história" (Figura 9). O contexto, representado pela tela da televisão desligada, não deve influir no percurso desse sujeito automotivado. Essa leitura da relação entre as influências ambientais e a psique empreendedora é uma representação extrema da sociedade individualizada, a síntese do que representa o neoliberalismo em termos sociais e culturais.

A grande narrativa de sucesso do blog é um mapeamento dos modos de autogestão do capital humano pela via da autoajuda. Resiliência, motivação, perseverança, transpiração, inspiração e capacidade de liderança estão entre os atributos ideais de um mundo povoado por semideuses, a sociedade de empreendedores. Esses atributos são traduzidos como aptidões exigidas pelo mercado de trabalho na atualidade, são formas de subjetivação que correspondem às transformações radicais desse mercado e as tornam naturalizadas, incorporadas à vida reprogramada pela ótica do neoliberalismo. Byung-Chul (2013) aponta que a sociedade

Figura 9: Charge do Blog Geração de Valor de 9 de abril de 2018
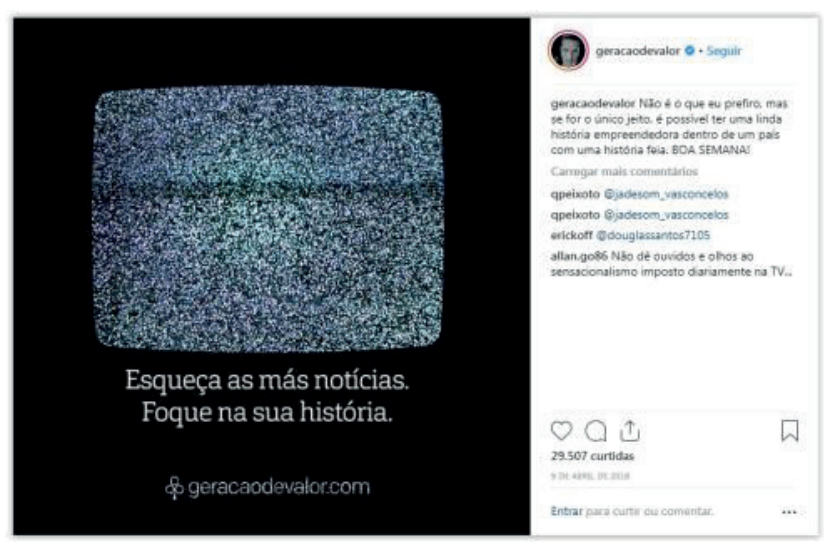

Fonte: Instagram do Blog Geração de Valor (2019). Disponível em: < https://www.instagram.com/geracaodevalor/>. Acesso em: 2 fev. 2019. 
da performance constituída como imperativo tem como efeitos colaterais o cansaço, a depressão, as consequências da aplicação de parâmetros inumanos a seres humanos. Observando a cena construída pelo Geração de Valor, apesar da predominância da afirmação eufórica do culto à performance, em dado momento irrompe uma fissura nessa narrativa que, mesmo sendo pontual, parece-nos muito significativa do quanto essa realidade construída é baseada na crença na sociedade positiva descrita por Byung-Chul (2013) e na adesão a ela. Essa ruptura é da ordem do acontecimento, no sentido discutido por Prado (2013, p. 495): como um "conceito [que] encarna uma ruptura nos estados das coisas".

O acontecimento em questão é a tragédia criminosa ocorrida na cidade mineira de Brumadinho, interior de Minas Gerais, em 25 de janeiro de 2019, provocada pelo rompimento de uma barragem de rejeitos de mineração da megacorporação Vale - considerado um dos maiores acidentes de trabalho do mundo nos últimos tempos, por profissionais a serviço da empresa serem a maioria dos mais de 300 mortos.

Esse acontecimento aparece como ruptura narrativa, uma vez que é o contraponto ao imaginário social construído pelo Blog Geração de Valor, por uma fatal coincidência. Uma das vítimas desse crime ambiental e humano foi Márcio Mascarenhas, chamado de "amigo" por Flávio Augusto, em postagem no dia posterior ao rompimento da barragem (Figura 10). O empresário, dono da pousada que ficava à beira do Córrego do Feijão, completamente destruída pela onda de lixo químico, foi proprietário de uma escola de línguas, a rede Number One, vendida ao grupo de Flávio Augusto em 2017. Na postagem, o texto vem acompanhado de uma foto que circulou como sendo de Brumadinho; porém, a fotografia de um homem abraçando um bombeiro do estado de Minas Gerais foi tirada em uma situação anterior a esse evento.

O texto de Flávio Augusto é a antítese da psicologia positiva predominante no blog: "Nossa rede está em choque com o ocorrido. [...] Não somos nada. Apenas estamos provisoriamente por aqui. RIP". Em termos de composicionalidade hermenêutica, essa "moral da história" contrasta com a perspectiva narrativa hegemônica da autoajuda empreendedora e seu caráter motivacional. O tom melancólico da mensagem, a dramaticidade da imagem e o reconhecimento da finitude e fragilidade do ser humano contrastam com o super-homem projetado como empreendedor, com características de semideus, inabalável e indestrutível em relação às suas convicções, aos seus planos e sonhos. A vida e os projetos de futuro de centenas de trabalhadores e de habitantes 

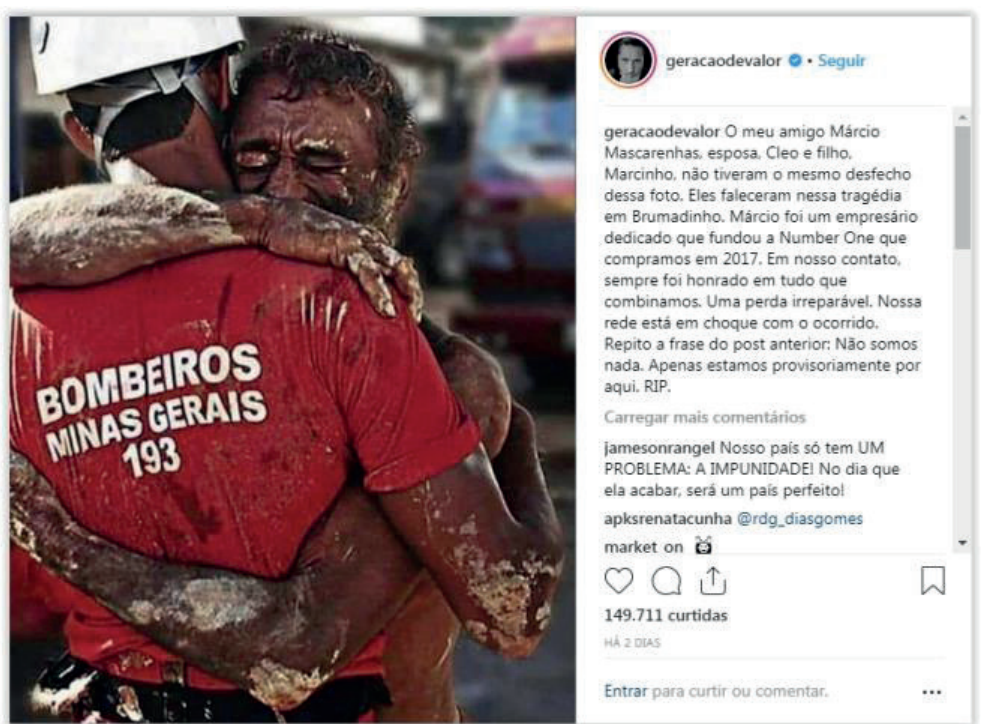

Fonte: Instagram do Blog Geração de Valor (2019). Disponível em: < https://www.instagram.com/geracaodevalor/>. Acesso em: 2 fev. 2019.

e visitantes de Brumadinho foram interrompidos pela morte abrupta, brutal, injustificável. Concluímos, a partir do cenário trágico derivado das ações da Vale, que o poder econômico do mercado não foi sinônimo de progresso e de bem-estar para todos; muito pelo contrário.

A fissura narrativa promovida pelo acontecimento de Brumadinho evidencia a autoajuda empreendedora como ela é: um sistema de crenças com nítidas limitações, uma convocação biopolítica para que os indivíduos se ajustem à ordem econômica e social hegemônica. A perversa ironia é que esse acontecimento seja um sintoma do próprio capitalismo, na perspectiva da sociedade de risco (BECK, 2011). Para Beck (2011), o risco é o principal resultado do modo de produção capitalista contemporâneo. No lugar da riqueza para todos, temos a distribuição generalizada de tragédias ambientais, de acidentes e incidentes que atingem grandes multidões, no sentido inverso da sociedade da abundância, que justificava o capitalismo em sua gênese.

\section{Considerações finais}

As narrativas são modelos de mundo e, simultaneamente, modelos do self(BROckMEIER; HARRÉ, 2003). Os sujeitos se constroem narrativamente e atribuem sentido ao contexto social. Os elementos narrativos apresentados por Bruner (1991) revelam especificidades dessa relação entre linguagem, subjetividade e sociedade. É por meio 
de suas contribuições que analisamos como as narrativas do empreendedorismo buscam constituir um elo social, imaginado em torno da figura do empreendedor como modelo de cultura. Ainda de acordo com Brockmeier e Harré (2003, p. 531), "narrativa é o nome para um repertório especial de instruções e normas sobre o que deve e o que não deve ser feito na vida, e, como um caso individual deve ser integrado a um padrão generalizado e culturalmente estabelecido".

As "charges" de autoajuda do Blog Geração de Valor constituem uma grande narrativa de sucesso, que atrela a felicidade pessoal e profissional a uma jornada vitoriosa de empreendimento de si mesmo. Nessa jornada, a psicologia positiva aplicada prega o individualismo, a competitividade, a fé cega na vocação empreendedora e a transformação contínua de si, como forma de adequação ao capitalismo flexível, que acirra a precarização do trabalho e o desmonte das leis e garantias trabalhistas. Ou seja, essa expressão do capitalismo comunicacional serve ao processo de produção do sujeito neoliberal, que deve se ajustar às transformações do mundo do trabalho, e não o contrário. Se o capitalismo cada vez menos contempla a questão humana, é preciso forjar uma nova subjetividade para assimilar esse capitalismo flexível como nova normalidade. A forma de justificação do sistema, ou seja, a positivação desse cenário está fortemente baseada na ideologia do empreendedorismo, publicizada por um sem número de agentes, que ocupam a cena midiática com sua nova racionalidade, suas narrativas, seus exemplos, seus discursos inspiracionais.

Estamos entre dois extremos: a fé cega na sociedade positiva, que representa o esvaziamento político dos indivíduos; e o reconhecimento de que estamos à deriva, sujeitos à corrosão do caráter discutida por Sennett (2007). A construção narrativa da realidade (BRUNER, 1991) do Blog Geração de Valor evidencia tanto o capitalismo comunicacional em pleno funcionamento quanto o seu tensionamento pela realidade que irrompe como acontecimento, ou como sintoma na experiência cotidiana do trabalho na atualidade. Em ambos os casos, a narrativa materializa os sentidos do sucesso e fracasso, a alienação e a consciência crítica. Essa é a dimensão política da narrativa, dissimulada pela autoajuda empreendedora.

\section{Referências}

ANGENOT, Marc. El discurso social: los limites históricos de lo pensable y lo decible. Buenos Aires: Siglo XXI, 2010.

BAJTÍN, Mikhail. Estética de la creación verbal. Buenos Aires: Siglo XXI, 2008. BAKHTIN, Mikhail. (Voloshinov). Marxismo e filosofia da linguagem. São Paulo: Hucitec, 1997. 
BECK, Ulrich. Sociedade de risco: rumo a uma outra modernidade. São Paulo: Ed. 34, 2011. BOLTANSKI, Luc; CHIAPELLO, Ève. O novo espírito do capitalismo. São Paulo: Martins Fontes, 2009.

BROCKMEIER, Jens; HARRÉ, Rom. Narrativa: problemas e promessas de um paradigma alternativo. Psicologia: Reflexão e Crítica, v. 16, n. 3, p. 525-535, 2003.

BRUNER, Jerome. The narrative construction of reality. Critical Inquiry, v. 18, n. 1, p. 1-21, 1991.

BUONANNO, Milly. Histórias de vida exemplares. Biografias. MATRIZes, São Paulo, v. 5, n. 1, p. 63-84, 2011.

BYUNG-CHUL, Han. La sociedad de la transparencia. Herder Editorial: Barcelona, 2013.

CASAQUI, Vander. Abordagem crítica da cultura da inspiração: produção de narrativas e o ideário da sociedade emprendedora.

E-Compós, v. 20, n. 2, p. 1-18, 2017.

DARDOT, Pierre; LAVAL, Christian. A nova razão do mundo: ensaio sobre a sociedade neoliberal. São Paulo: Boitempo, 2016.

DRUCKER, Peter F. Inovação e espírito empreendedor: prática e princípios. São Paulo: Cengage Learning, 2011.

EHRENBERG, Alain. O culto da performance: da aventura empreendedora à depressão nervosa. Aparecida, SP: Ideias \& Letras, 2010.

ENDEAVOR BRASIL/SEBRAE. 50 histórias para inspirar sua jornada empreendedora: um exemplo para chamar de seu. São Paulo: Endeavor Brasil / Sebrae, s/d. Disponível em:
$<$ http://info.endeavor.org.br/tp-ebook-50historias>. Acesso em: 5 fev. 2020.

FIGUEIREDO, Camila B. Simurro.

Celebridades empreendedoras e narrativas inspiracionais: pacotes biopolíticos de Bel Pesce e Flávio Augusto da Silva (Geração de Valor) no âmbito da comunicação e do consumo. 2018. 240 f. Dissertação (Mestrado) - Programa de Mestrado em Comunicação e Práticas de Consumo, Escola Superior de Propaganda e Marketing, 2018.

FOUCAULT, Michel. Birth of Biopolitics. New York: Palgrave Macmillan, 2008.

FREIRE FILHO, João (Org.) Ser feliz hoje: reflexões sobre o imperativo da felicidade. Rio de Janeiro: Ed. FGV, 2010.

GALLO, Carmine. TED: falar, convencer, emocionar; como se apresentar para grandes plateias. São Paulo: Saraiva, 2014.

JAMESON, Fredric. Arqueologías del futuro: el deseo llamado utopía y otras aproximaciones de ciencia ficción. Madrid: Ed. Akal, 2009.

KEDROWICZ, April A.; TAYLOR, Julie L. Shifting Rhetorical Norms and Electronic Eloquence: TED Talks as formal presentations. Journal of Business and Technical Communication, v. 30, n. 3, p. 352-377, 2016. MARÍN-DÍAZ, Dora L. Autoajuda e educação: uma genealogia das antropotécnicas contemporâneas. 2012. 310 f. Tese (Doutorado em Educação)-Faculdade de Educação, Universidade Federal do Rio Grande do Sul, Porto Alegre, 2012.

PRADO, José L. Aidar. Decifrando os pontos sintomáticos do capitalismo comunicacional. In: ; PRATES, Vinícius (Org.). Sintoma e fantasia no capitalismo comunicacional. 
São Paulo: Estação das Letras e Cores, 2017.

p. 13-25.

Política do acontecimento. Famecos,

v. 20, n. 2, p. 495-520, maio/ago. 2013.

SENNETT, Richard. A corrosão do caráter:

consequências pessoais do trabalho no novo

capitalismo. Rio de Janeiro: Record, 2007.

A cultura do novo capitalismo. Rio de

Janeiro: Record, 2006.

SINATO, Angelina. Os discursos globalizados

do empreendedorismo social: narrativas

heroicas, mundos possíveis e consumo

simbólico. 2016. 228 f. Dissertação (Mestrado)

- Programa de Mestrado em Comunicação

e Práticas de Consumo, Escola Superior de

Propaganda e Marketing, 2016.

\section{Informações sobre 0 artigo}

Resultado de projeto de pesquisa, de dissertação, tese: 0 artigo é resultado parcial do projeto de pesquisa: "Narrativas no contexto da cultura empreendedora: estratégias discursivas e mercadológicas de institucionalidades, marcas e subjetividades", desenvolvido no PósCom UMESP.

Fontes de financiamento: 0 presente trabalho foi realizado com apoio do CNPq, Conselho Nacional de Desenvolvimento Científico e Tecnológico - Brasil (processo no. 303434/2019-8); e da Fundação de Amparo à Pesquisa do Estado de São Paulo (FAPESP), processo no. 2019/14365-7.

Considerações éticas: não se aplica.

Declaração de conflito de interesses: não se aplica.

Apresentação anterior: não se aplica.

Agradecimentos/Contribuições adicionais: não se aplica. 


\section{The role of narrative in the project of entrepreneurial society and in the culture of inspiration}

\section{Abstract:}

This work aims to deal with narratives as an object of study, in the context of entrepreneurship and the culture of inspiration, based on the theory of Bruner (1991) on the elements that characterize the narrative. As an empirical object, we analyze the entrepreneurial self-help micronarratives of Blog Geração de Valor, called "cartoons", in light of Bruner's narrative theory. When we approach critically the theme of entrepreneurship, we understand the fundamental role of inspirational narratives, which articulate discursive context and materiality, the spirit of time and subjectivity, economy and life trajectories.

\section{Keywords:}

Communication and consumption. Entrepreneurial culture. Culture of inspiration. Narrative. Discourse.

\section{El papel de la narrativa en el proyecto de la sociedad emprendedora y en la cultura de la inspiración}

\section{Resumen:}

Este trabajo tiene como objetivo tratar de las narrativas como objeto de estudio, en el contexto del emprendedorismo y de la cultura de la inspiración, teniendo como base la teoría de Bruner (1991) sobre los elementos que caracterizan la narrativa. Como objeto empírico, analizamos las micronarrativas de autoayuda emprendedora del Blog Geração de Valor, llamadas "caricaturas", a la luz de la teoría narrativa de Bruner. $\mathrm{Al}$ abordar críticamente el tema del emprendedorismo, comprendemos el papel fundamental de las narrativas inspiracionales, que articulan contexto y materialidad discursiva, espíritu del tiempo y subjetividad, economía y trayectorias de vida.

\section{Palabras clave:}

Comunicación y consumo. Cultura emprendedora. Cultura de la inspiración. Narrativa. Discurso.

\author{
Vander Casaqui \\ Doutor pelo Programa de Pós-Graduação em Ciências \\ da Comunicação da Escola de Comunicações e Artes \\ da Universidade de São Paulo, com Pós-Doutorado pela \\ Universidade Nova de Lisboa. Docente do Programa de \\ Pós Graduação em Comunicação Social da Universidade \\ Metodista de São Paulo-UMESP. \\ Universidade Metodista de São Paulo, São Bernardo do \\ Campo, São Paulo, Brasil. \\ E-:mail: vcasaqui@yahoo.com.br \\ ORCID: https://orcid.org/0000-0001-7823-9861
}

